University of Nebraska - Lincoln

DigitalCommons@University of Nebraska - Lincoln

Publications from USDA-ARS / UNL Faculty

U.S. Department of Agriculture: Agricultural

Research Service, Lincoln, Nebraska

November 2005

\title{
Developmental sequences for simulating crop phenology for water-limiting conditions
}

\author{
Gregory S. McMaster \\ USDA-ARS, Great Plains Systems Research Unit, Fort Collins, CO, greg.mcmaster@ars.usda.gov \\ Wally Wilhelm \\ University of Nebraska-Lincoln, wally.wilhelm@ars.usda.gov
}

A. B. Frank

USDA-ARS, Northern Great Plains Research Laboratory

Follow this and additional works at: https://digitalcommons.unl.edu/usdaarsfacpub

Part of the Agricultural Science Commons

McMaster, Gregory S.; Wilhelm, Wally; and Frank, A. B., "Developmental sequences for simulating crop phenology for water-limiting conditions" (2005). Publications from USDA-ARS / UNL Faculty. 69. https://digitalcommons.unl.edu/usdaarsfacpub/69

This Article is brought to you for free and open access by the U.S. Department of Agriculture: Agricultural Research Service, Lincoln, Nebraska at DigitalCommons@University of Nebraska - Lincoln. It has been accepted for inclusion in Publications from USDA-ARS / UNL Faculty by an authorized administrator of DigitalCommons@University of Nebraska - Lincoln. 


\title{
Developmental sequences for simulating crop phenology for water-limiting conditions
}

\author{
Gregory S. McMaster ${ }^{\mathrm{A}, \mathrm{D}}, W . W$. Wilhelm $^{\mathrm{B}}$, and A. B. Frank ${ }^{\mathrm{C}}$ \\ ${ }^{A}$ USDA-ARS, Great Plains Systems Research Unit, 2150 Centre Avenue, Building D, \\ Suite 200, Fort Collins, CO 80526, USA. \\ ${ }^{B}$ USDA-ARS, Soil \& Water Conservation Research Unit, 120 Keim Hall, East Campus, \\ University of Nebraska, Lincoln, NE 68583, USA. \\ ${ }^{\mathrm{C}}$ USDA-ARS (retired), Northern Great Plains Research Laboratory, PO Box 459, Mandan, ND 58554-0459, USA. \\ ${ }^{\mathrm{D}}$ Corresponding author. Email: Greg.McMaster@ars.usda.gov
}

\begin{abstract}
The timing, duration, and pace of developmental events, or phenology, are among the many responses of plants to limited soil water. Understanding and predicting plant responses to availability of soil water are important in improving the efficacy of management practices. However, the first steps towards gaining this understanding, summarising the complete developmental sequence of the shoot apex and correlating the timing of these events, have rarely been reported. Also, the effect of water-limiting conditions on crop phenology and shoot apex development is variable. The objective of this paper is to present the developmental sequence of the wheat (Triticum aestivum L.), barley (Hordeum vulgare L.), and corn (Zea mays L.) shoot apices and correlate events in these sequences with growth stages for both well-watered and water-limiting conditions. We note that phenological responses to water availability occur at 3 different scales: among crops, among cultivars of a crop, and among growth stages within a cultivar or crop. Clearly, genotype $\times$ environment interaction affects the accuracy of predicting phenology. However, the fact that plants develop in an orderly, predictable pattern allows a general foundation for synthesising the complete sequence of developmental events of the shoot apex and correlate these with growth stages when water is not limiting. These patterns and relationships are the foundation to build upon in quantifying our understanding of crop phenology under water-limiting environments.
\end{abstract}

Additional keywords: growth stages, water stress, shoot apex, development, GDD, growing degree-days; GEI, genotype by environment interaction.

\section{Introduction}

Plants display diverse adaptations and responses to limited water that often are subdivided into two general categories: dehydration avoidance and tolerance. Developmental responses can be placed into either classification, but generally, phenological responses (i.e. the timing of growth stages as plants move through their life cycle) are considered to be important means of avoidance by altering when the growth stage occurs or how long the stage exists in the life of the individual or the crop.

How plants respond developmentally and the timing of these events (commonly referred to as growth stages) to limited soil water depend on factors including the timing, intensity, and history of the water stress and species, as well as cultivars within species. As an illustration, in most instances, temperate annual small-grain cereals reach growth stages earlier under water stress (e.g. McMaster 1997). However, Abrecht and Carberry (1993) showed that severe water stress for 19 days after sowing delayed silk and tassel initiation in corn, primarily by slowing the rate of leaf appearance, but subsequent growth stages were reached earlier. Muchow and Carberry (1989) also found that water stress slowed leaf appearance and decreased leaf size, but did not affect final leaf number or corn phenology. Stout et al. (1978) reported that water stress delayed inflorescence development and extended the period of leaf and stem growth for one perennial sorghum [Sorghum bicolor (L.) Moench.] cultivar, but found the opposite responses for another cultivar.

Factors contributing to the complexity of assessing the effect of water stress on the timing of developmental events of many crops include: (1) widely used growth stages usually only distinguish stages easily observed in the field, and omit important developmental events occurring at the shoot apex, (2) the complete developmental sequence of the shoot apex for many crops has not been summarised, 
(3) timing of developmental events at the shoot apex has rarely been correlated with growth stages under wellwatered conditions (i.e. the genetic blueprint of how the crop develops), much less under water-limiting conditions (an environmental effect on the genotype), and (4) literature reporting phenological responses of crops under the full range of water availability often is not available or is contradictory. Some confusion likely is caused by the often-present genotype $\times$ environment interaction (GEI), as demonstrated for 12 winter wheat cultivars by McMaster and Wilhelm (2003). Furthermore, plant water stress responses may be dissimilar in terms of direction, duration, and intensity across growth stages and studies. For instance, about 25\% less thermal time was required for winter wheat to reach anthesis and physiological maturity when soil water was limiting, yet only about a 5\% reduction in thermal time was observed for flag leaf appearance, and no significant difference was found for time of jointing (McMaster and Wilhelm 2003).

Clearly, a complete synthesis and quantification of shoot apex developmental events correlated with growthstage scales for water-limiting and non-limiting conditions are needed for better understanding and prediction of crop phenology across the full range of potential environments. This need is particularly important for plant growth simulation models, as many models lack sufficient developmental detail to be used effectively to aid breeding programs and crop management decisions. These problems are exacerbated when users attempt to parameterise a new model or decision support system or an existing model for a new crop. Often the modeller or practitioner is unfamiliar with the crop or phenology in general, or does not have available data to correctly parameterise the phenology model.

This paper presents the complete shoot apex developmental sequence correlated with growth stages for 3 crops (wheat, barley, and corn) and discusses some key crop-specific developmental and phenological responses to water stress.

\section{Methods}

Information summarising the developmental sequences of shoot apices and correlating them with phenology for varying levels of water availability was derived or developed in a series of steps. In the first step we identified and selected an appropriate growth-stage scale for each crop.

The second step was to summarise the complete developmental sequence of the shoot apex under well-watered conditions for each crop. A basic framework had been developed for winter wheat by McMaster (1997). Barley and corn, both annual grasses with somewhat similar developmental sequences, were added. These summaries then provided the genetic pattern of development for the generic form (not cultivarspecific) of each crop without environmental limitations.

The third step was to identify shoot apex developmental events missing from growth-stage scales. This was necessary because these scales normally consider only growth stages that are readily discernible in the field without magnification or dissection to reveal the shoot apex. The timing of these developmental events relative to critical growth stages was identified.

Step 4 was to determine how limited soil water altered the timing of events or the interval between growth stages. Wherever possible, we used published data to determine expected responses. A great deal more literature exists on the phenology of wheat and other small grains than for corn. In addition, we used discussions with other scientists and our experience to estimate thermal time when data were limited or unavailable.

The last step was to describe how selected cultivars of a species differed in development or developmental response from the generic plant. Often the literature only reported differences among a few cultivars for a limited number of specific growth stages, so knowledge for other growth stages is uncertain. We also briefly evaluated genotype $\times$ environment interactions when information was available.

\section{Results and discussion}

\section{Growth stages and scales}

Many growth-stage scales have been developed for each crop, with some popular and recommended scales identified by Frank et al. (1997). Some scales apply to more than one crop, including the Haun Growth Stage Scale (Haun 1973) and BBCH Growth Stage Scale (Lancashire et al. 1991). Several growth-stage scales, each having a slightly different emphasis, are commonly used for wheat and barley: Haun (Haun 1973), Feekes (Large 1954), and Zadoks (Zadoks et al. 1974). The most commonly used growth-stage scale for corn was developed by Ritchie et al. (1986), based on initial work by Hanway (1963).

We take this opportunity to note that these commonly called growth-stage scales, might properly be called developmental-stage scales since they describe plant development (the process by which plants, organs, or cells pass through various identifiable stages during their life cycle), not growth (the permanent increase in volume or mass of an individual or organ with time; Wilhelm and McMaster 1995). However, since these scales are widely known as growth-stage scales and the stages as growth stages (not developmental stages) by the vast majority of readers and practitioners, we will use the terms growth-stage and growthstage scales throughout this paper.

Many factors (e.g. photoperiod, water and nutrient availability, $\mathrm{CO}_{2}$, salinity) influence the timing of growth stages, but clearly temperature is generally regarded as the most significant factor (McMaster 1997, 2005). Numerous approaches have been used to characterise temperature and are grouped under the general term of thermal time. Thermal time is normally represented as one of many forms of growing degree-days (GDD). Many functions have been used and compared (e.g. McMaster and Smika 1988; McMaster and Wilhelm 1997) and some debate exists on where to best measure temperature (e.g. McMaster et al. 2003).

In the last several decades another representation of thermal time has been based on leaf appearance rates (i.e. the 
phyllochron) or leaf number (e.g. Haun 1973; Bauer et al. 1984; Kirby and Appleyard 1984; McMaster et al. 1992). This approach is converted to GDD by multiplying the number of leaves between events by the GDD required to produce a leaf (the phyllochron). Unfortunately, accuracy of equations that predict the phyllochron has been poor (McMaster and Wilhelm 1995).

The phyllochron varies among cultivars and crops: winter wheat is often 100-115 GDD (McMaster 1997), spring wheat and barley 65-85 GDD (Frank and Bauer 1995), and corn 30-50 GDD (Vinocur and Ritchie 2001; Wilhelm and Varvel 1998). Although the phyllochron often is essentially linear in field conditions, examples of shifts have been observed. For instance, Wuethrich (1997) reported a dramatic shift in the phyllochron for corn near the V10 stage (when the collar of the 10th leaf is visible), Warrington and Kanemasu (1983) observed a shift for corn at the V12 stage in a growth chamber, and Baker et al. (1986), among others, have shown a shift near the double-ridge growth stage for wheat. Care must be taken in directly comparing GDD values as different methods of calculating GDD and base temperatures are used (McMaster and Wilhelm 1997).

\section{Shoot apex developmental sequences under non-limiting soil water conditions}

The developmental sequence for winter wheat presented by McMaster et al. (1992) and fully documented by McMaster (1997) has proved useful as a template for other crops, particularly for annual cereal grasses (Fig. 1). In this diagram, events occurring at the shoot apex (e.g. leaf, spikelet, and floret primordia initiation) are correlated with specific growth stages for a winter wheat plant. Thermal time in the time line is represented for both the GDD and leaf number approaches. The use of leaf number to estimate the duration for certain intervals, such as during the grain-filling interval (i.e. from anthesis to physiological maturity), does not imply that leaves are appearing during this period; rather it is an alternative representation of time (Rickman and Klepper 1995).

Conversion from winter wheat to winter barley (Fig. 2) is readily accomplished because of the great similarity between the 2 crops (e.g. Bonnett 1966; Kirby and Appleyard 1984), with only 3 differences that merit mentioning here. Firstly, barley is an indeterminate plant, and therefore does not have

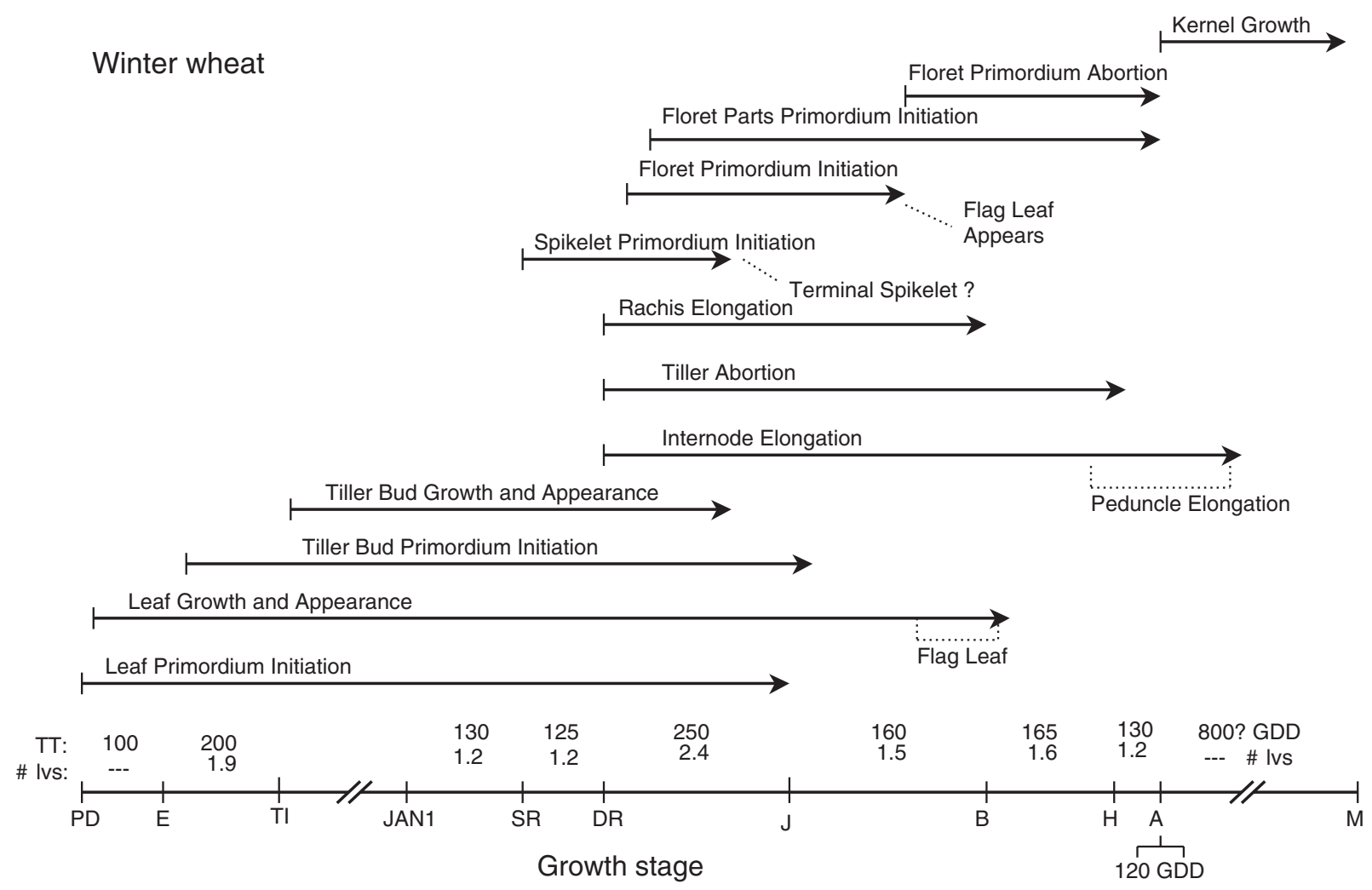

Fig. 1. Winter wheat shoot apex developmental sequence correlated with growth stages (Large 1954) for conditions with no stresses. The time line is presented as thermal time (TT, in growing degree-days, GDD, using $0^{\circ} \mathrm{C}$ base and Method 1 of McMaster and Wilhelm 1997) and number of leaves (\# lvs). Question marks indicate areas of uncertainty or significant variation among cultivars. See Fig. 6 for identification of growth stages on the time line. Adapted from McMaster et al. (1992). 


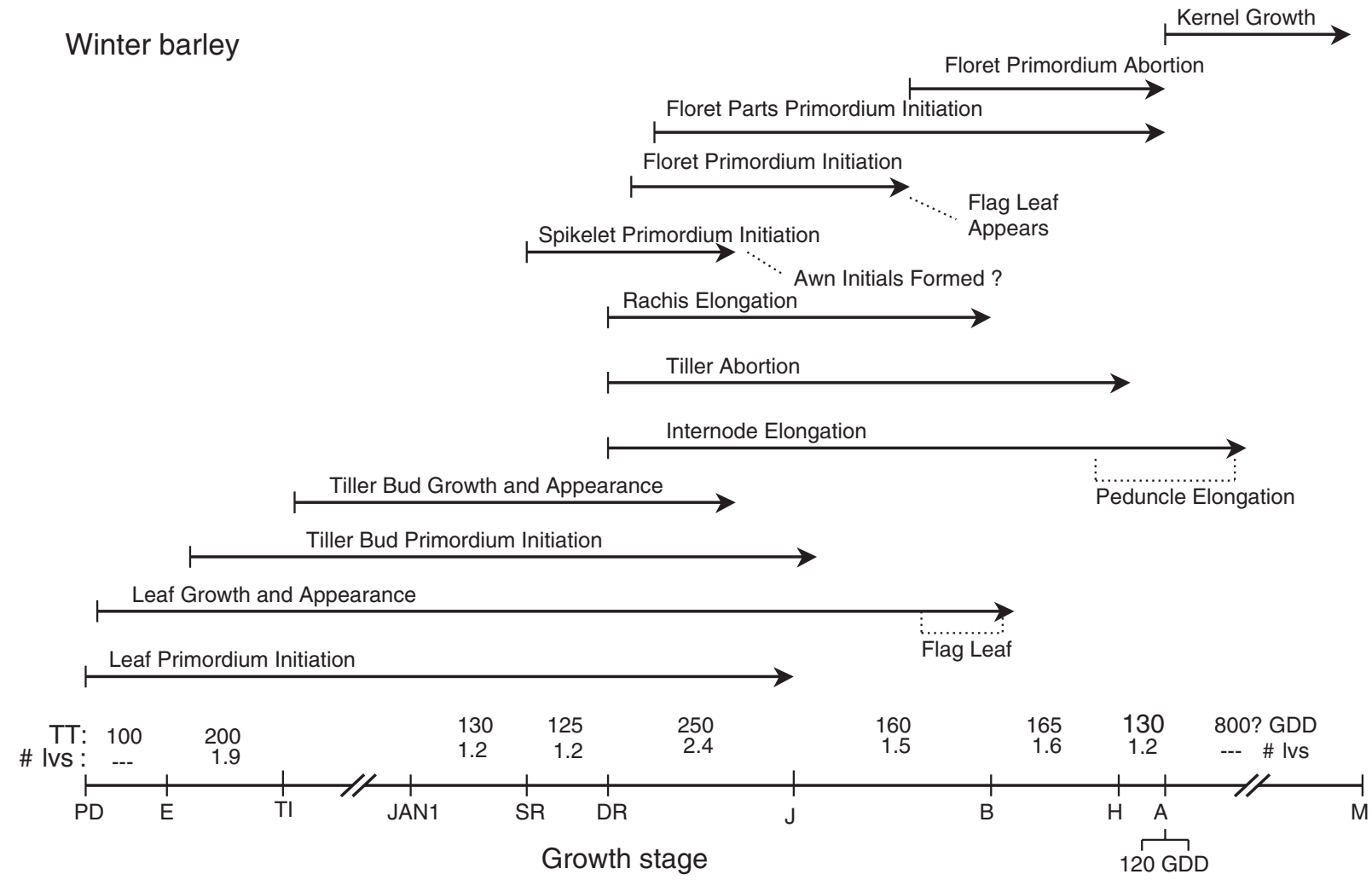

Fig. 2. Winter barley shoot apex developmental sequence correlated with growth stages (Large 1954) for conditions with no stresses. The time line is presented as thermal time (TT, in growing degree-days, GDD, using $0^{\circ} \mathrm{C}$ base and Method 1 of McMaster and Wilhelm 1997) and number of leaves (\# lvs). Question marks indicate areas of uncertainty or significant variation among cultivars. See Fig. 7 for identification of growth stages on the time line.

a terminal spikelet like wheat (Bonnett 1966). However, the formation of awn initials signifies the end of spikelet initiation that will result in a fully developed spikelet (Kirby and Appleyard 1984; Frank et al. 1992). Secondly, the structure of the barley spike differs from wheat in that barley spikelets only develop one mature kernel (wheat can develop up to 6 kernels under favourable conditions in central spikelets), and at each node position on the rachis, barley develops either 1 spikelet for 2-rowed varieties or 3 spikelets for 6-rowed varieties (Bonnett 1966; Kirby and Appleyard 1984; Wilhelm and McMaster 1996). Fortunately, for purposes of the developmental sequence diagram, this second difference has little impact. The last distinction is that rates of various developmental processes for wheat and barley differ, particularly a slightly smaller phyllochron for many barley varieties (Frank and Bauer 1995) and reduced thermal time from booting through maturity for barley (Bauer et al. 1990).

For both winter wheat and barley, vernalisation is required to induce reproductive events at the shoot apex. The switch from vegetative to reproductive development in the apex effectively occurs at the single- to double-ridge stage. All leaf initials formed after the single-ridge stage do not further differentiate and grow into leaves. Only initials formed prior to this stage will result in leaves that appear later. The switch is complete by the double-ridge stage as the lower ridge is the leaf initial and the upper ridge is the spikelet initial. Generally, either the GDD or leaf number approach adequately predicts the timing of growth stages occurring after the vernalisation requirement has been satisfied. Determining when the vernalisation requirement is satisfied is often difficult and has been addressed recently by Streck et al. (2003). However, for many environments in the Northern Hemisphere, accumulating thermal time after 1 January is a simplification that works well because the vernalisation requirement has normally been satisfied by this time (McMaster et al. 1992). For Southern Hemisphere applications, 1 July could be substituted to produce comparable results.

The developmental sequence is the same for spring wheat (Fig. 3) and spring barley (Fig. 4) as for winter wheat and winter barley, respectively (Bonnett 1966; Kirby and Appleyard 1984; McMaster 1997, 2005). The timing of growth stages from single ridge through maturity remain the same, with a possible exception that spring varieties tend to produce slightly fewer leaves after jointing than 


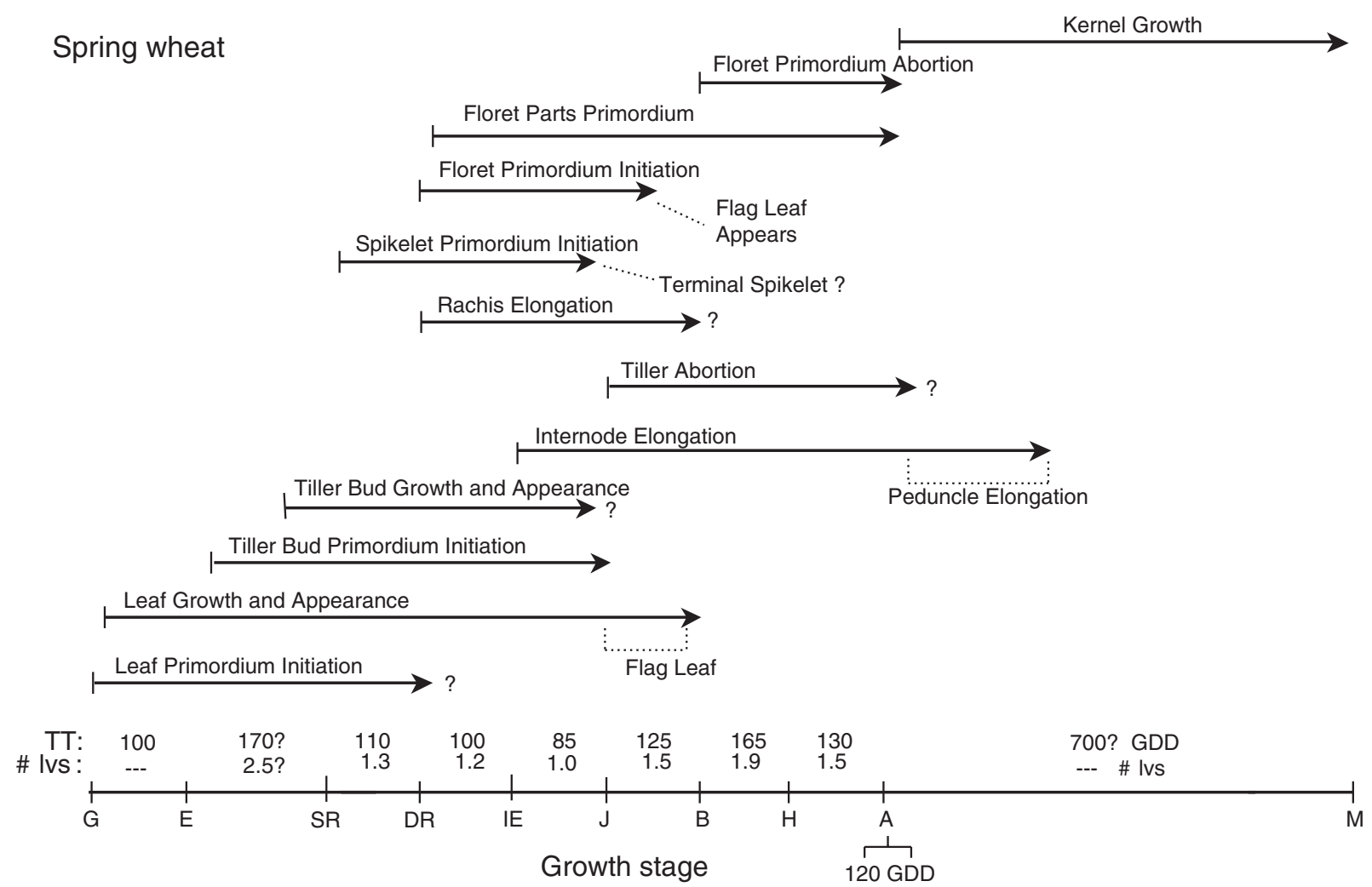

Fig. 3. Spring wheat shoot apex developmental sequence correlated with growth stages (Large 1954) for conditions with no stresses. The time line is presented as thermal time (TT, in growing degree-days, GDD, using $0^{\circ} \mathrm{C}$ base and Method 1 of McMaster and Wilhelm 1997) and number of leaves (\# lvs). Question marks indicate areas of uncertainty or significant variation among cultivars. See Fig. 8 for identification of growth stages on the time line.

winter varieties (McMaster 1997). The primary difficulty when moving from winter to spring varieties is predicting when the single-ridge growth stage occurs. This is because spring wheat varieties differ considerably in the number of leaves produced prior to single ridge. For instance, essentially all spring wheat varieties grown in the northern Great Plains are referred to as 8-leafed varieties because under almost all conditions they produce 8 leaves on the main stem (Bauer et al. 1984). Only one variety, James, is considered a 7-leafed variety, and no varieties are known to produce more than 8 leaves. This suggests that these varieties are primarily responding to the genotype and not the environment to determine total leaf number. Alternatively, it may be that the environments where spring wheat is grown do not vary sufficiently for significant GEI to be displayed. (Note, the environment, particularly water and $\mathrm{N}$ availability, mainly affects leaf size and senescence timing.) However, other spring wheat varieties (as defined by showing little vernalisation response), particularly those grown in Australia, are known to produce more than 8 leaves, perhaps as many as 11 leaves (Rawson 1970). Since we know that approximately 5.5 leaves are formed after single ridge (Figs 3 and 4), the number of leaves formed prior to single ridge will be the final leaf number minus 5.5. Considering a 7-leafed cultivar, 1.5 leaves would be produced prior to single ridge, and for an 8-leafed cultivar 2.5 leaves would be produced. For cultivars that form many leaves, for example 11, the number of leaves at single ridge will be influenced by planting date where earlier dates will result in more leaves formed than later planting dates.

Returning to the 7- and 8-leafed cultivars as a verification of this conceptual developmental model, either 7 or 8 leaf primordia, respectively, must be formed prior to single ridge to have this number of leaves appear. This leads to the question of whether enough primordia can be formed so early in the life cycle. Three assumptions are required for this to occur: (1) at least 2 leaf primordia are present in the embryo (McMaster 1997) cites references indicating that 3-4 leaf primordia are present in the seed), (2) the plastochron (i.e. leaf primordia initiation) is 2-3 times the phyllochron (i.e. the rate of leaf appearance; McMaster (1997) cites studies supporting this), and (3) 2.5 leaves appear by single ridge for an 8-leafed variety. Given these assumptions, we need to account for 6 leaf primordia initiated from germination to single ridge (after subtracting the 2 primordia in the embryo). A plastochron rate of 2.4 times the leaf 


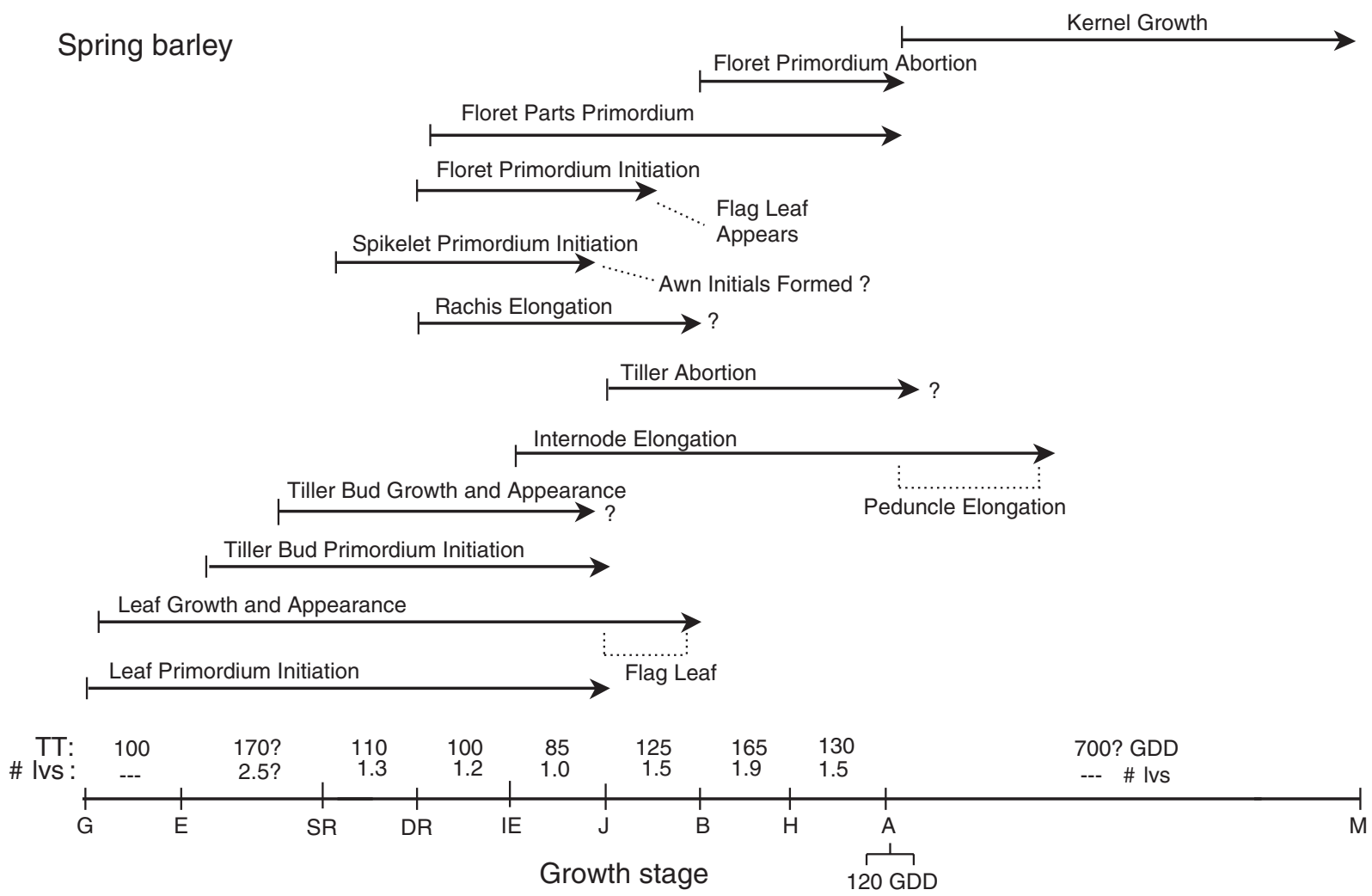

Fig. 4. Spring barley shoot apex developmental sequence correlated with growth stages (Large 1954) for conditions with no stresses. The time line is presented as thermal time (TT, in growing degree-days, GDD, using $0^{\circ} \mathrm{C}$ base and Method 1 of McMaster and Wilhelm 1997) and number of leaves (\# lvs). Question marks indicate areas of uncertainty or significant variation among cultivars. See Fig. 9 for identification of growth stages on the time line. Adapted from McMaster (2005).

appearance rate multiplied by 2.5 leaves needed to appear would account for 6 leaf primordia (i.e. $2.4 \times 2.5=6$ ), well within the reported values. If we assume 3 leaf primordia in the embryo, then to produce 5 primordia would require a plastochron rate of 2 times the leaf appearance rate, which has often been observed. Bonnett (1966) also states that nearly all the leaf primordia that will be produced can be found by the time the second leaf of barley is well grown.

The similarity of shoot apex development among grasses makes the wheat and barley templates a useful concept and process pattern for describing development in corn (Fig. 5), although there are several challenges in doing so. Firstly, the growth-stage scales normally used differ between small grains and corn. We selected the commonly accepted scale of Ritchie et al. (1986), which is based almost entirely on external, easily observed characteristics, to document stage of corn development. Secondly, it is also important to recognise that staminate and pistillate flowers form in separate inflorescences in the monoecious corn plant. This attribute is both an advantage and disadvantage in describing development. The separate flowers are more easily observed, but lack of synchrony of development of male and female inflorescences and flowers caused by genetic or environmental factors, or their interactions, can complicate attempts to concisely summarise the processes. Thirdly, detailed descriptions of corn development have been based on many types of corn, e.g. dent (both hybrid and inbred), pop, flint, and sweet. Randolph (1936) found no significant differences in development of the kernel among dent, flint, and sweet corn. Bonnett (1966) states that morphological characteristics of infloresences of dent and sweet corn are similar. We assume that any variation in developmental sequences among types is inconsequential. As with wheat and barley, the relationships or timing of events shown in Fig. 5 were gathered from published reports, and important details will be discussed below.

The apical meristem may cease producing leaf primordia as early as V3 (when the collar of the 3rd leaf is visible); however, leaf appearance and growth continue until about V12 (Ritchie et al. 1986) even though many of the leaves are hidden from view within the whorl at that stage. Appearance of later leaves is a result of internode elongation not growth of leaves themselves.

Internode elongation has been reported to begin as early as stage V6 (Ritchie et al. 1986) or as late as V8-V10 (Bonnett 1966). Bonnett (1966) states that the number of 


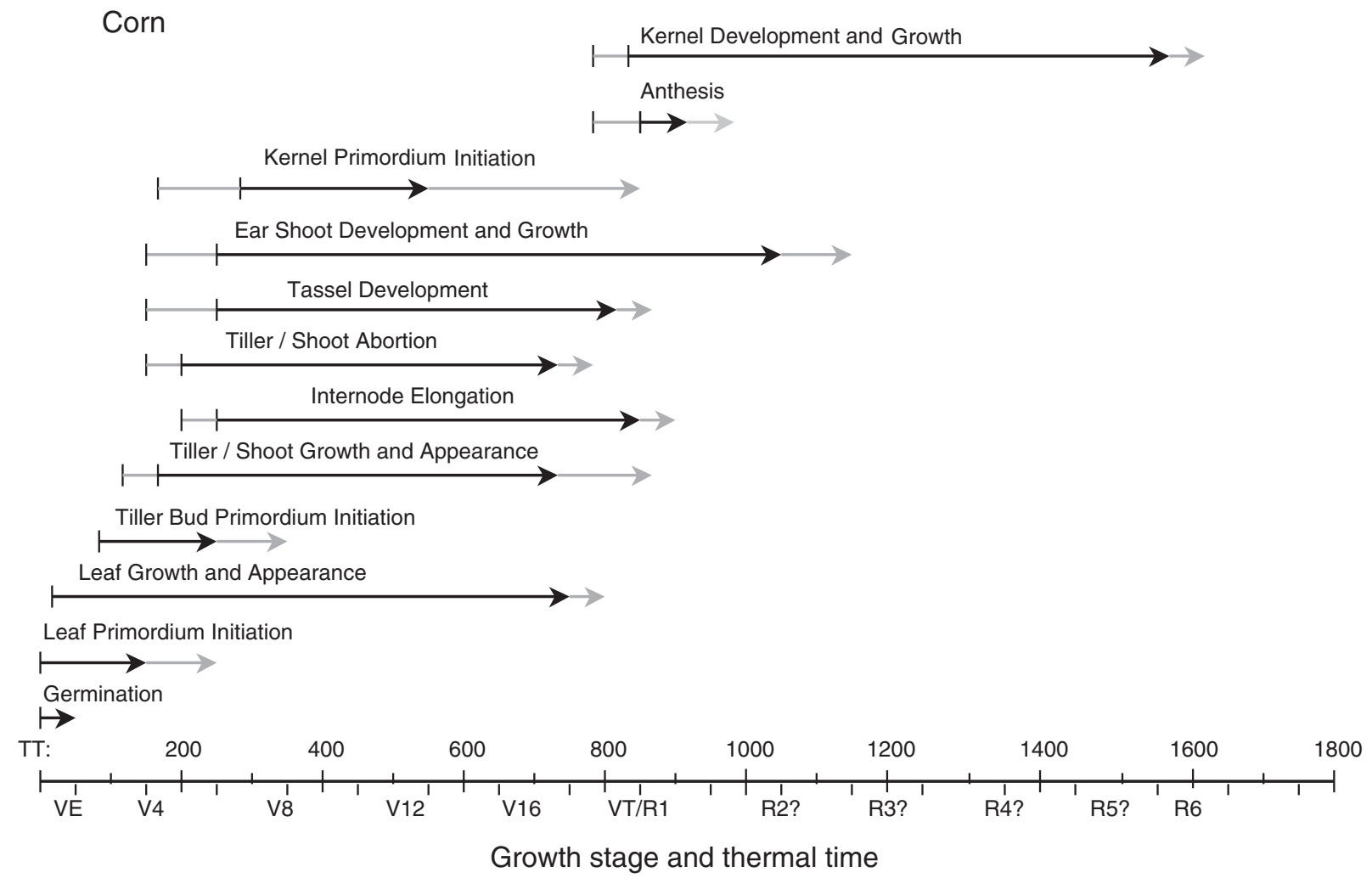

Fig. 5. Corn shoot apex developmental sequence correlated with growth stages for conditions with no stresses. The time line is presented as thermal time (TT, in growing degree-days, GDD, using $10^{\circ} \mathrm{C}$ base and $30^{\circ} \mathrm{C}$ upper threshold and Method 2 of McMaster and Wilhelm 1997) and growth stages (Ritchie et al. 1986). Dimmed sections at the beginning and end of lines showing the duration of developmental processes represent variation in literature reports of when the process is initiated or completed. See Fig. 10 for identification of growth stages on the time line. Adapted from Wilhelm and Varvel (1998).

leaves on the plant is not a reliable guide to the time when internode elongation begins. Regardless of the time, internode elongation signals the end of lateral bud formation (Bonnett 1966; Baba and Yamazaki 1996) and the transition to development of inflorescences in both apical (Bonnett 1966) and lateral meristems (Bonnett 1966; Baba and Yamazaki 1996). This also ends effective leaf primordia initiation that will develop further into leaves, as is the case with wheat and barley. Growth of basal lateral buds 'that have completed development' remains vegetative and normally growth ceases at this transitional stage, but they can develop into tillers if the apical meristem is removed (Sato and Sasaki 1987). Lateral buds that exist only as 'small protrusions' at the time when internodes begin to elongate have the potential to become ears; the uppermost of these buds becomes the primary ear. Buds that are "not yet visible as protrusions' disappear from the leaf axials (Baba and Yamazaki 1996).

Kiesselbach (1949) indicated that tassel differentiation started 2 weeks after emergence. The first sign of tassel development is a noticeable elongation of the apicial meristem (similar to single ridge in wheat and barley) and appearance of primordia that become tassel branches or spikelets (Bonnett 1948). Development of the branches on the ear shoot and tassel generally starts about the same time (Kiesselbach 1949). Bonnett (1966) indicated that early in development, the external appearance of first-order tassel branches and spikelet initials is the same. Leng (1951) reported that the time from planting to tassel initiation ranged from 22 to 31 days in 8 inbreds grown at Urbana, IL in 1948. There was no relationship between days from planting to tassel differentiation and planting to anthesis (i.e. inbreds with short intervals between planting and tassel differentiation may or may not have short periods from planting to anthesis).

Differentiation of the ear begins in buds in leaf axils at about the same time as differentiation of the tassel at the apical meristem, but ear development generally lags behind tassel development (Bonnett 1948; Kiesselbach 1949). The beginning of this process can be identified by a marked elongation of the previously hemispheric meristem and development of branch initials. According to Bonnett (1948), the number of rows of kernels in the mature ear is determined by the number of rows of branch initials that differentiate on 
the developing ear. Each branch initial divides into 2 spikelet initials and each spikelet produces 1 fertile floret. Tollenaar and Daynard (1978) found that spikelet initiation ceased 7 days prior to silking in 2 early corn hybrids grown near Guelph, Ontario, Canada. Ritchie et al. (1986) stated that at V15, silks are starting to grow in the uppermost ear and the tassel may be visible from the whorl at V17.

Anthesis (i.e. pollen shed from the tassel) and silking (i.e. stigmas extruding from the ear and receptive to pollen) growth stages occur nearly simultaneously, but pollen shed begins slightly before silking, reflecting the pattern observed in early development, that processes in the ear lag behind similar processes in the tassel. Pollen is first shed from florets in the upper middle section of the central axis of the tassel and proceeds basipetally, acropetally, and distally over a period of 7 days or more (Weatherwax 1916; Bassetti and Westgate 1994), as is the case for wheat and barley. The interval between the onset of pollen shed and silking, the anthesis-silking interval (ASI), is important in determining grain set, which in turn is critical in defining final yield (Campos et al. 2004). The length of the ASI interval (i.e. the degree of synchronisation between silking and pollen shed within the plant) is positively correlated with the severity of stress under some conditions (Hall et al. 1981).

Kernel development and growth of both the embryo and endosperm start immediately after fertilisation and follow the normal patterns for annual grasses (Bonnett 1966; McMaster 1997). Black layer formation has been documented to signal physiological maturity in many corn genotypes
(Daynard and Duncan 1969; Rench and Shaw 1971; Carter and Poneleit 1973).

\section{Missing developmental events in growth-stage scales}

Once the shoot apex developmental sequence has been summarised, identifying shoot apex developmental events missing from different growth-stage scales is readily noted. For instance in wheat, the developmental events of single ridge, double ridge, and terminal spikelet primordium are widely recognised as key processes setting yield potential. The timing of these developmental events relative to growth stages is identified in Figs 1 and 3. Similarly for barley, single ridge and double ridge are also important shoot apex developmental events. However, rather than the terminal spikelet stage for wheat, the equivalent barley stage is 'awn initials formed' because barley is an indeterminate plant. In corn, similar shoot apex developmental events have not been widely recognised as important, although it is not clear why this is so.

\section{Phenology under water-limiting conditions}

Once the developmental sequence of the shoot apex is associated with growth stages for well-watered soil conditions, adjustments for severe, but not terminal, waterlimiting conditions are required in order to derive values listed in Figs 6-10. The general rule for wheat, barley, and corn is that as soil water becomes less available, developmental events are reached sooner and/or the duration of the interval (especially the duration of grain filling) is reduced if there is an effect (e.g. McMaster 1997 cites numerous references;

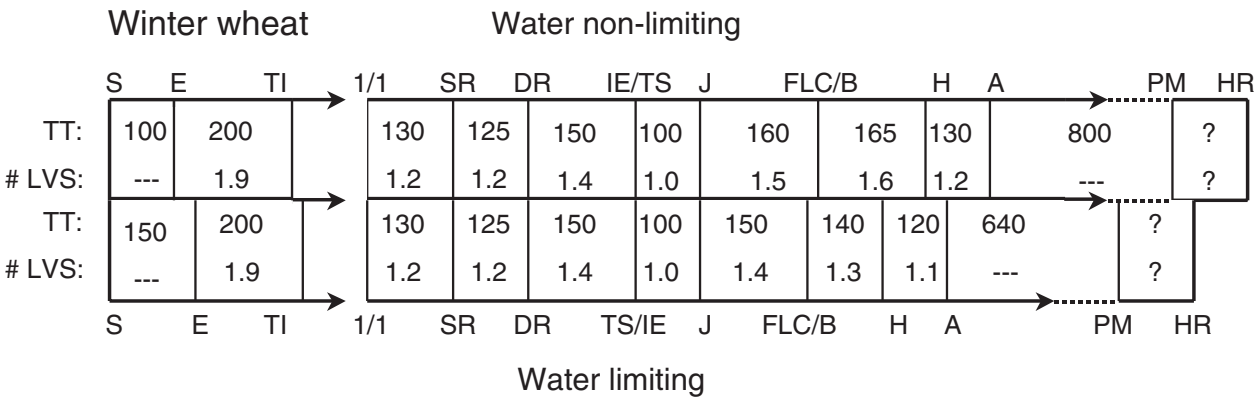

$$
\begin{array}{ll}
\mathrm{S}=\text { Sowing } & \mathrm{DR}=\text { Double Ridge } \\
\mathrm{E}=\text { Emergence } & \mathrm{IE}=\text { Internode Elongation } \\
\mathrm{TI}=\text { Tiller Initiation } & \mathrm{TS}=\text { Terminal Spikelet } \\
\mathrm{SR}=\text { Single Ridge } & \mathrm{J}=\text { Jointing }
\end{array}
$$

$$
\begin{aligned}
& \text { FLC }=\begin{array}{r}
\text { Flag Leaf } \\
\text { Complete }
\end{array} \\
& \mathrm{B}=\text { Booting } \\
& \mathrm{H}=\text { Heading }
\end{aligned}
$$

Fig. 6. Winter wheat phenology for both water non-limiting and limiting conditions. Intervals between stages are shown as both the thermal time (TT in growing degree-days, GDD, using $0^{\circ} \mathrm{C}$ base and Method 1 of McMaster and Wilhelm 1997) and the number of leaves (\# lvs) for a generic cultivar. Values for water non-limiting conditions are derived from Fig. 1, and for limiting soil water are primarily derived from McMaster and Smika (1988) and McMaster and Wilhelm (2003). Note that the 'number of leaves' option after the Flag Leaf Complete/Booting stage is not meant to imply that more leaves are appearing; rather it is using the phyllochron as the measure of thermal time. 
Water non-limiting

\begin{tabular}{|c|c|c|c|c|c|c|c|c|c|c|c|c|c|}
\hline & $S$ & $T$ & $1 / 1$ & SR & $\mathrm{R}$ & IE/AI & $\mathrm{J}$ & & $\mathrm{H}$ & A & & PI & \\
\hline TT: & 100 & 200 & 130 & 125 & 150 & 100 & 160 & 165 & 13 & & 800 & & $?$ \\
\hline \# LVS: & --- & 1.9 & 1.2 & 1.2 & 1.4 & 1.0 & 1.5 & 1.6 & 1. & & -- & & ? \\
\hline TT: & 150 & 200 & 130 & 125 & 150 & 100 & 150 & 140 & 120 & 640 & & $?$ & \\
\hline \# LVS: & --- & 1.9 & 1.2 & 1.2 & 1.4 & 1.0 & 1.4 & 1.3 & 1.1 & --- & & $?$ & \\
\hline & $S$ & $E$ & $1 / 1$ & SR & $\mathrm{DR}$ & $\mathrm{I} / \mathrm{IE}$ & $\mathrm{J}$ & & $\mathrm{H}$ & A & PI & & IR \\
\hline
\end{tabular}

$$
\begin{array}{ll}
\mathrm{S}=\text { Sowing } & \mathrm{DR}=\text { Double Ridge } \\
\mathrm{E}=\text { Emergence } & \mathrm{IE}=\text { Internode Elongation } \\
\mathrm{TI}=\text { Tiller Initiation } & \mathrm{Al}=\text { Awn Initials } \\
\mathrm{SR}=\text { Single Ridge } & \mathrm{J}=\text { Jointing }
\end{array}
$$

$$
\begin{aligned}
& \begin{array}{l}
\text { FLC }=\begin{array}{r}
\text { Flag Leaf } \\
\text { Complete }
\end{array} \\
\mathrm{B}=\text { Booting } \\
\mathrm{H}=\text { Heading }
\end{array}
\end{aligned}
$$

Fig. 7. Winter barley phenology for both water non-limiting and limiting conditions. Intervals between stages are shown as both the thermal time (TT in growing degree-days, GDD, using $0^{\circ} \mathrm{C}$ base and Method 1 of McMaster and Wilhelm 1997) and the number of leaves (\# lvs) for a generic cultivar. Values for water non-limiting conditions are derived from Fig. 2. Note that the 'number of leaves' option after the Flag Leaf Complete/Booting stage is not meant to imply that more leaves are appearing; rather it is using the phyllochron as the measure of thermal time.

\section{Spring wheat Water non-limiting}

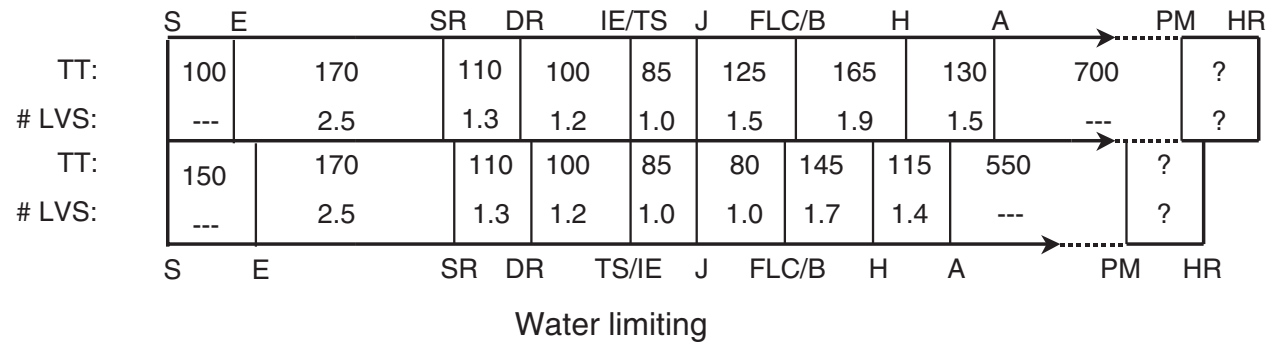

$$
\begin{array}{ll}
\mathrm{S}=\text { Sowing } & \mathrm{DR}=\text { Double Ridge } \\
\mathrm{E}=\text { Emergence } & \mathrm{IE}=\text { Internode Elongation } \\
\mathrm{TI}=\text { Tiller Initiation } & \mathrm{TS}=\text { Terminal Spikelet } \\
\mathrm{SR}=\text { Single Ridge } & \mathrm{J}=\text { Jointing }
\end{array}
$$

$$
\begin{aligned}
& \begin{array}{l}
\text { FLC }=\begin{array}{r}
\text { Flag Leaf } \\
\text { Complete }
\end{array} \\
B=\text { Booting } \\
\mathrm{H}=\text { Heading }
\end{array}
\end{aligned}
$$

Fig. 8. Spring wheat phenology for both water non-limiting and limiting conditions. Intervals between stages are shown as both the thermal time (TT in growing degree-days, GDD, using $0^{\circ} \mathrm{C}$ base and Method 1 of McMaster and Wilhelm 1997) and the number of leaves or (\# lvs) for a generic cultivar. Values for water non-limiting conditions are derived from Fig. 3, and for limiting soil water are primarily derived from Bauer et al. (1984) and McMaster and Wilhelm (2003). Note that the 'number of leaves' option after the Flag Leaf Complete/Booting stage is not meant to imply that more leaves are appearing; rather it is using the phyllochron as the measure of thermal time.

Wilhelm and Varvel 1998). For instance, when combining 12 winter wheat varieties for 2 locations over 2 years, limiting soil water had little effect on the growth stages of jointing and flag leaf appearance, and increasingly greater effect on the growth stages of heading, anthesis, and physiological maturity (Table 1; McMaster and Wilhelm 2003). It should be noted that because soil water availability was not controlled, the degree of water stress tended to increase as physiological maturity was approached. Similar results were reported for spring barley (McMaster and Wilhelm 2003).

Campos et al. (2004) state that many corn growth stages occur earlier under water-limiting conditions, particularly 


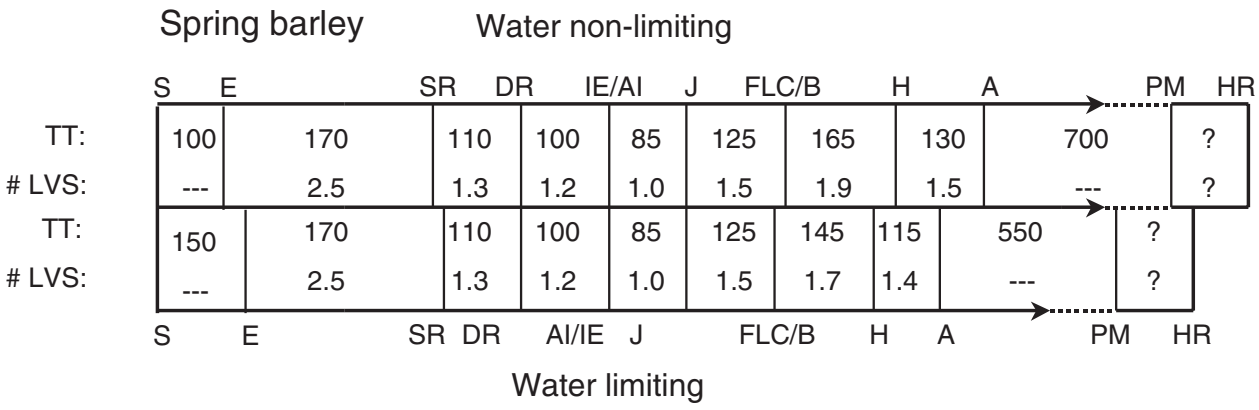

$\begin{array}{ll}\mathrm{S}=\text { Sowing } & \mathrm{DR}=\text { Double Ridge } \\ \mathrm{E}=\text { Emergence } & \mathrm{IE}=\text { Internode Elongation } \\ \mathrm{TI}=\text { Tiller Initiation } & \mathrm{AI}=\text { Awn Initials } \\ \mathrm{SR}=\text { Single Ridge } & \mathrm{J}=\text { Jointing }\end{array}$

$$
\begin{aligned}
& \text { FLC = Flag Leaf } \\
& \text { Complete } \\
& \mathrm{B}=\text { Booting } \\
& \mathrm{H}=\text { Heading }
\end{aligned}
$$$$
\text { A }=\text { Anthesis }
$$$$
\mathrm{PM}=\text { Physiological }
$$$$
\text { Maturity }
$$$$
\text { HR = Harvest Ripe }
$$

Fig. 9. Spring barley phenology for both water non-limiting and limiting conditions. Intervals between stages are shown as both the thermal time (TT in growing degree-days, GDD, using $0^{\circ} \mathrm{C}$ base and Method 1 of McMaster and Wilhelm 1997) and the number of leaves or (\# lvs) for a generic cultivar. Values for water non-limiting conditions are derived from Fig. 4, and for limiting soil water are primarily derived from Frank et al. (1992) and McMaster and Wilhelm (2003). Note that the 'number of leaves' option after the Flag Leaf Complete/Booting stage is not meant to imply that more leaves are appearing; rather it is using the phyllochron as the measure of thermal time.

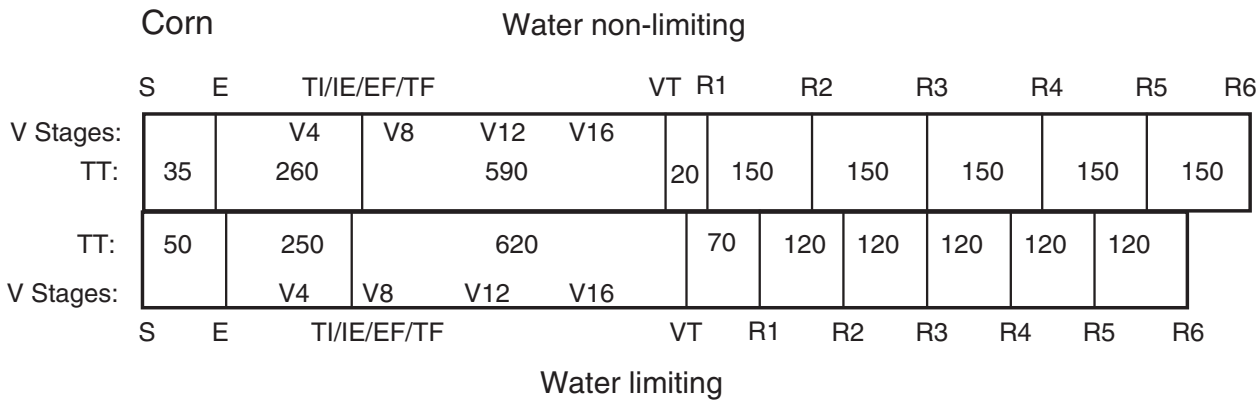

$$
\begin{aligned}
& \mathrm{S}=\text { Sowing } \\
& \mathrm{E}=\text { Emergence } \\
& \mathrm{TI}=\text { Tiller Initiation } \\
& \mathrm{EF}=\text { Ear Formation }
\end{aligned}
$$

$$
\begin{aligned}
& \mathrm{TF}=\text { Tassel Formation } \\
& \mathrm{IE}=\text { Internode Elongation } \\
& \mathrm{V \#}=\text { \# of Collared } \\
& \text { Leaves }
\end{aligned}
$$

$$
\begin{aligned}
& \text { VT }=\text { Tasseling } \\
& \text { R1 }=\text { Silking } \\
& \text { R2 }=\text { Blister } \\
& \text { R3 }=\text { Milk }
\end{aligned}
$$$$
\mathrm{R} 4=\text { Dough }
$$$$
\text { R5 = Dent }
$$$$
\text { R6 = Physiological }
$$$$
\text { Maturity }
$$

Fig. 10. Corn phenology for both water non-limiting and limiting conditions. Intervals between stages are shown as both the thermal time (TT in growing degree-days, GDD, using $10^{\circ} \mathrm{C}$ base and $30^{\circ} \mathrm{C}$ upper threshold and Method 2 of McMaster and Wilhelm 1997) and developmental stages (Ritchie et al. 1986) for a generic cultivar. Values for water non-limiting conditions are derived from Fig. 5, and for limiting soil water, values are from several literature reports including Hall et al. (1981), Abrecht and Carberry (1993), and Campos et al. (2004), and our observations.

those after R1 (silking). However, it does appear that both tasseling and silking are delayed under water-limiting conditions (Hall et al. 1981; Abrecht and Carberry 1993). Most importantly, water-limiting conditions reduce the synchronisation between pollen shed and silking, resulting in an increase in the ASI interval, and reduce final yield (Hall et al. 1981; Campos et al. 2004).
Thermal estimates provided in Figs 6-10 are for the extremes of well-watered soil and extremely dry soil where the plant is still able to survive. If soil water availability is between these 2 extremes, as usually is the case, timing of developmental events or durations of developmental stages will be intermediate to the extremes shown here. Further guidance on this is very difficult to provide because very 
few data are available to describe the relationship between these extreme values.

\section{Cultivar differences and genotype $\times$ environment interaction (GEI)}

Although the developmental sequence is similar for all genotypes within a species, genotypes may differ in their developmental rates, and certainly the environment will affect the rates. Unfortunately, there can also be a GEI, yet often the literature only reports differences among a few cultivars for a few specific growth stages.

Some cultivar-specific differences were noted in earlier sections and will not be repeated here. However, 2 growth stages for wheat, barley, and corn that are very cultivarspecific and often show a GEI are the beginning of anthesis and maturity, and therefore the duration of grain filling. McMaster and Wilhelm (2003) found that 12 winter wheat varieties responded in the same general manner to water stress in the experiment discussed above and shown in Table 1, but also showed that varieties differed in their responses, depending on growth stage and location/year, and found a definite GEI. Similarly, Carter and Poneleit (1973) reported significant genotype, environment, and GEI effects on duration of corn grain filling, but that the interaction term was minor compared with genotype, with the environment effect being intermediate to these 2 extremes.

Given the importance of the phyllochron and leaf number in predicting development, it was interesting that durum wheat, spring barley, crested wheatgrass [Agropyron desertorum (Fischer ex Link) Schultes], intermediate wheatgrass [Elytrigia intermedia (Host) Nevski:Syn:A. intermedium (Host) Beauv.], and reed canarygrass (Phalaris arundinacea $\mathrm{L}$.) did not show a significant cultivar $\times$ year interaction and spring wheat and western wheatgrass [Elymus smithii (Rybd.) Gould] only showed a minor cultivar $\times$ year interaction (Frank and Bauer 1995). These observations may reflect a stronger photoperiod response in the perennial species listed.

Table 1. Winter wheat phenological responses to limiting soil water Data are for means of 12 winter wheat varieties grown at 2 locations (Fort Collins and Akron, CO) for 2 years. Adapted from McMaster and Wilhelm (2003)

\begin{tabular}{lccc}
\hline Interval & $\begin{array}{c}\text { Irrigated } \\
\text { (GDD) }\end{array}$ & $\begin{array}{c}\text { Dryland } \\
\text { (GDD) }\end{array}$ & $\begin{array}{c}\text { Difference } \\
\text { (\%) }\end{array}$ \\
\hline 1 Jan. to Jointing & 484 & 486 & 100.4 \\
Jointing to Flag Leaf Complete & 158 & 152 & 96.2 \\
$\quad$ (begin Booting) & & & \\
Flag Leaf Complete to Heading & 164 & 143 & 87.2 \\
Heading to Anthesis & 133 & 117 & 88.0 \\
Anthesis to Maturity & 710 & 557 & 78.5 \\
\hline
\end{tabular}

${ }^{\mathrm{A}}[1-($ Irrigated GDD - Dryland GDD)/Irrigated GDD] $* 100$.

\section{Conclusions}

Three different scales of phenological responses to varying levels of limiting soil water exist: among crops, within cultivars of a crop, and among growth stages within a cultivar/crop. Clearly the reality of genotype $\times$ environment interaction confounds the accuracy of simulating phenology; however, the fact that plants develop in an orderly and predictable pattern allows a general foundation for synthesising the complete developmental sequence of the shoot apex and correlating this with growth stages. This paper presented templates for wheat, barley, and corn shoot apex developmental sequences correlated with growth stages, and showed how available soil water alters the timing of various growth stages. We hope that the ideas presented provide a foundation to build upon for these crops, as well as other crops, as we gain further understanding of soil water availability and crop phenology.

\section{References}

Abrecht DG, Carberry PS (1993) The influence of water deficit prior to tassel initiation on maize growth, development and yield. Field Crops Research 31, 55-69. doi: 10.1016/0378-4290(93)90050-W

Baba T, Yamazaki K (1996) Effects of phase transition on the development of lateral buds in maize. Crop Science 36, $1574-1579$.

Baker JT, Pinter PJ Jr, Reginato RJ, Kanemasu ET (1986) Effects of temperature on leaf appearance in spring and winter wheat cultivars. Agronomy Journal 78, 605-613.

Bassetti P, Westgate ME (1994) Floral asynchrony and kernel set in maize quantified by image analysis. Agronomy Journal 86, 699-703.

Bauer A, Black AL, Frank AB (1984) Estimation of spring wheat leaf growth rates and anthesis from air temperature. Agronomy Journal 76, 829-835.

Bauer A, Black AL, Frank AB, Vasey EH (1990) Agronomic Characteristics of Spring Barley in the Northern Great Plains. North Dakota Agricultural Experiment Station (Fargo) Bulletin No. 523, $48 \mathrm{pp}$.

Bonnett OT (1948) Ear and tassel development in maize. Missouri Botanical Gardens Annals 35, 269-287.

Bonnett OT (1966) Inflorescences of maize, wheat, rye, barley, and oats: their initiation and development. University of Illinois College of Agriculture, Agricultural Experiment Station Bulletin 721, $105 \mathrm{pp}$.

Campos H, Cooper M, Habben JE, Edmeades GO, Schussler JR (2004) Improving drought tolerance in maize: a view from industry. Field Crops Research 90, 19-34. doi: 10.1016/j.fcr.2004.07.003

Carter MW, Poneleit CG (1973) Black layer maturity and filling period variation among inbred lines of corn (Zea mays L.). Crop Science 13, 436-439.

Daynard TB, Duncan WG (1969) The black layer and grain maturity in corn. Crop Science 9, 473-476.

Frank AB, Bauer A (1995) Phyllochron differences in wheat, barely, and forage grasses. Crop Science 35, 19-23.

Frank AB, Bauer A, Black AL (1992) Effects of air temperature and fertilizer nitrogen on spike development in spring barley. Crop Science 32, 793-797.

Frank AB, Cardwell VB, Ciha AJ, Wilhelm WW (1997) Growth staging in research and crop management. Crop Science 37, 1039-1040. 
Hall AJ, Lemcoff JH, Trapani N (1981) Water stress before and during flowering in maize and its effects on yield, its components, and their determinants. Maydica 29, 19-38.

Hanway JJ (1963) Growth stages of corn (Zea mays L.). Agronomy Journal 55, 487-492.

Haun JR (1973) Visual quantification of wheat development. Agronomy Journal 65, 116-119.

Kiesselbach AT (1949) The structure and reproduction of corn. Nebraska Agriculture Experiment Station Bulletin 161, 96 pp.

Kirby EJM, Appleyard M (1984) 'Cereal development guide.' 2nd edn (Arable Unit, National Agricultural Centre: Coventry, UK)

Lancashire PD, Bleiholder H, Van den Boom T, Langeluddeke P, Strauss R, Weber E, Witzenberger A (1991) A uniform decimal code for growth stages of crops and weeds. Annals of Applied Biology 119, 561-601.

Large EC (1954) Growth stages in cereals. Plant Pathology 3, 128-129.

Leng ER (1951) Time-relationships in tassel development of inbred and hybrid corn. Agronomy Journal 43, 445-449.

McMaster GS (1997) Phenology, development, and growth of the wheat (Triticum aestivum L.) shoot apex: a review. Advances In Agronomy 59, 63-118.

McMaster GS (2005) Centenary review: phytomers, phyllochrons, phenology and temperate cereal development. Journal of Agricultural Science, Cambridge 143, 137-150. doi: 10.1017/ S0021859605005083

McMaster GS, Smika DE (1988) Estimation and evaluation of winter wheat phenology in the central Great Plains. Agricultural and Forest Meteorology 43, 1-18. doi: 10.1016/0168-1923(88)90002-0

McMaster GS, Wilhelm WW (1995) Accuracy of equations predicting the phyllochron of wheat. Crop Science 35, 30-36.

McMaster GS, Wilhelm WW (1997) Growing degree-days: one equation, two interpretations. Agricultural and Forest Meteorology 87, 291-300. doi: 10.1016/S0168-1923(97)00027-0

McMaster GS, Wilhelm WW (2003) Simulating wheat and barley phenological responses to water and temperature stress. Journal of Agricultural Science, Cambridge 141, 129-147. doi: 10.1017/S0021859603003460

McMaster GS, Wilhelm WW, Morgan JA (1992) Simulating winter wheat shoot apex phenology. Journal of Agricultural Science, Cambridge 119, 1-12.

McMaster GS, Wilhelm WW, Palic DB, Porter JR, Jamieson PD (2003) Spring wheat leaf appearance and temperature: extending the paradigm? Annals of Botany 91, 697-705. doi: 10.1093/aob/mcg074

Muchow RC, Carberry PS (1989) Environmental control of phenology and leaf growth in a tropically adapted maize. Field Crops Research 20, 221-236. doi: 10.1016/0378-4290(89)90081-6
Randolph LF (1936) Developmental morphology of the caryopsis in maize. Journal of Agricultural Research 53, 881-916.

Rawson HM (1970) Spikelet number, its control and relation to yield per ear in wheat. Australian Journal of Biological Sciences 23, $1-15$.

Rench WE, Shaw RH (1971) Black layer development in corn. Agronomy Journal 63, 303-305.

Rickman RW, Klepper BL (1995) The phyllochron: where do we go in the future? Crop Science 53, 44-49.

Ritchie SW, Hanway JJ, Benson GO (1986) How a corn plant develops. Special Report No. 48, Iowa State University of Science and Technology, Cooperative Extension Service, Ames, IA.

Sato K, Sasaki S (1987) Effects of shoot apex excision and leaf cutting on development of axillary shoots in maize plants. Nihon Sakumotsu Gakkai Kiji 56, 351-355.

Stout DG, Kannangara T, Simpson GM (1978) Drought resistance of Sorghum bicolor. 2. Water stress effects on growth. Canadian Journal of Plant Science 58, 225-233.

Streck NA, Weiss A, Baenziger PS (2003) A generalized vernalization response function for winter wheat. Agronomy Journal 95, 155-159.

Tollenaar M, Daynard TB (1978) Kernel growth and development at two positions on the ear of maize (Zea mays). Canadian Journal of Plant Science 58, 189-197.

Vinocur MG, Ritchie JT (2001) Maize leaf development biases caused by air-apex temperature differences. Agronomy Journal 93, $767-772$.

Warrington IJ, Kanemasu ET (1983) Corn growth response to temperature and photoperiod II. Leaf-initiation and leaf-appearance rates. Agronomy Journal 75, 755-761.

Weatherwax P (1916) Morphology of the flowers of Zea mays. Torrey Botanical Club Bulletin 43, 127-143.

Wilhelm WW, McMaster GS (1995) Importance of the phyllochron in studying development and growth in grasses. Crop Science 35, 1-3.

Wilhelm WW, McMaster GS (1996) Spikelet and floret naming scheme for grasses with a spike inflorescence. Crop Science 36, 1071-1073.

Wilhelm WW, Varvel GE (1998) Vegetative development of corn under various N management strategies. In '1998 Agronomy Abstract'. pp. 94. (ASA: Madison, WI)

Wuethrich K (1997) Vegetative and reproductive phenology of fourteen hybrids of dent corn (Zea mays L.). MS thesis, Purdue University, Indiana.

Zadoks JC, Chang TT, Konzak CF (1974) A decimal code for the growth stages of cereals. Weed Research 14, 415-421.

Received 7 March 2005, accepted 20 October 2005 